\title{
CORRESPONDENCE
}

To the Editor of the Aeronautical Journal

\section{AN AIR TARGET FOR ARTILLERY}

SrR,--In response to my invitation to designers and others, to produce an air target which could be employed for the aerial practice of artillery (see January number of this Journal, page 11), Mr. Alan Owston, a member of the Society residing at Yokohama, has forwarded a picture post-card showing a number of "koi," or carp, made of some light fabric, attached to masts, and flying in the breeze ; also one of the actual carp, about 8 feet in length. The mouth of the fish is stitched to a circular hoop, the tail is open at the ends ; a bridle is fixed to the hoop at the mouth, and attached to a tall mast, and the wind passing through the carp's body keeps it inflated and flying at an angle whose incidence varies with the strength of the wind; these fish are flown on festive occasions.

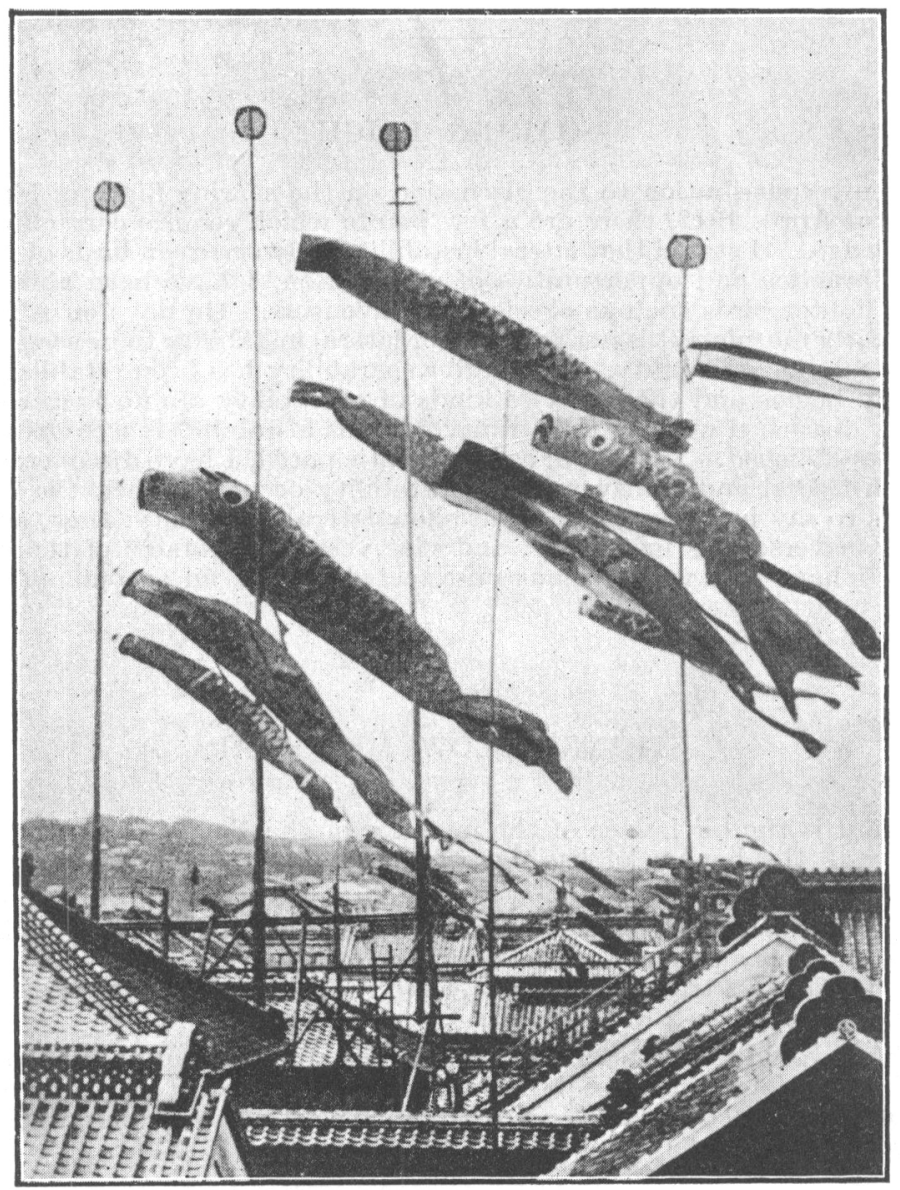

Mr. Owston's idea is that one of these carp might be towed by an aeroplane, being attached thereto by a piano wire, which would run off a small reel; he suggests that "failing some better device for handling this target, it should be folded up like a flag, and "broken out' when the aeroplane was in full flight."

The idea seems well worth following up. The first thing to do is to get one of our pilots to experiment with the fish at the end of a thousand yards of towing wire; the wire would be wound on a reel, and at the end of the run would presumably have to be 
cut loose, so as to avoid any danger of complication in turning and landing. The initial experiments could of course be made with a short length of wire, merely with a view to ascertaining the best method of fixing up the reel and attaching the wire, so as to avoid risk of interference with any of the controls. Obviously an aeroplane for this purpose should be driven by a tractor screw. Such experiments could only be carried out over unoccupied land, or over an area subject to the necessary safety precautions. If the experiments were successful, the next step could be considered, viz. : how to fire at the target without endangering the pilot of the aeroplane. This could be managed under certain conditions, but would not be a very simple matter; the precautions would have to be of such a nature as to make it impossible to shoot the pilot or the aeroplane by mistake. It is not necessary to enter into the nature of these precautions now ; the question is to prove the feasibility or otherwise of towing the target at the end of a thousand yards of towing wire.

Perhaps some of the readers of the Journal will be sufficiently interested to try the experiment with the fish, which can be lent for the purpose. If the experiment is successful on a small scale, it would be desirable to repeat it on a larger scale with a fish at least 30 feet in length.

$$
\text { F. G. Stone, COL., R.A. }
$$

\section{SOARING FLIGHT}

SrR,--In my contribution to the discussion on the soaring flight of birds, published in your issue of April, 1912, there are a few points which require correction in the light of later knowledge. I stated that lateral instability only occurs in birds of heavy loading. With further practice and opportunities of observation, I have been able to see lateral instability in lighter birds such as cheels and scavengers. On days on which instability occurs in the early morning, it is not unusual for lateral instability to be seen first, followed by dorso-ventral axis instability. Then after soarability has been established transverse axis instability begins and the first two kinds of soarability are no longer observed. It is only in very disturbed weather that transverse axis instability is seen before widespread soarability is established. Although, as I had anticipated, I have discovered exceptional cases in which lateral and transverse axis instability occur together, the rule still holds good. This is to say in air in which birds show lateral instability, they, as a rule, show no signs of transverse axis instability, and vice versa. The facts of the case are com. plicated, and I have met with various unexpected results, an account of which I hope to publish on a latter occasion.

E. H. HANKIN.

\section{STRINGFELLOW MEMORIAL}

July, 1912.

SIR,-Chard is the birthplace of the inventor of the English Aeroplane, upon John Stringfellow rests the honour of having been the first man to make an engine-driven aeroplane, which flew in the year 1848 .

Being a friend of the inventor, and having seen the original machine in its working shed, I have taken it upon myself to issue this circular for the purpose of soliciting contributions to enable a tribute to be erected to the memory of one who rendered such great service to his country and to science.

This tribute would take the form of an Imperishable Bronze Wreath, to be appended to the obelisk of the family memorial to Stringfellow in the cemetery at Chard with appropriate inscription. The stone curbing surrounding the grave would have a neat palisading surmounting it with aeroplanes in relief upon it. A tablet will also be erected over the porch of Stringfellow's late home.

The amount of money required to enable the foregoing proposals to be carried out is not a large one, and is estimated at about fifty pounds ( $\$ 50)$.

I am, yours faithfully,

JAMES GILLINGHAM.

Prospect House,

Chard, Somerset. 